Tohoku J. Exper. Med., 1963, 80, 329 337

\title{
Hyperpigmentation of the Skin with DOPA-uria of a Newborn
}

\author{
(A Peculiar Sign of an Infant Born of a Thyrotoxic \\ Mother Treated with Methimazol)
}

By

\author{
Tsuneo Arakawa, Yoshiro Wada, Keiya Tada and Hisao Ito \\ From the Department of Pediatrics, Faculty of Medicine, Tohoku \\ University, Sendai; Director: Prof. Ts. Arakawa
}

(Received for publication, August 3, 1963)

An infant with hyperpigmentation of the skin born of a thyrotoxic mother with methimazol medication was sent to our Clinic from the Obstetric Department for the purpose of examining the cause of this hyperpigmentation. This paper will show that an excessive amount of thyroxine transferred into fetus from a thyrotoxic mother was the factor responsible for the development of hyperpigmentation of the skin of the newborn in question.

\section{REPORT OF CASE}

T.A., a girl, was born on February 5, 1963, after an uneventful pregnancy and delivery, weighing $3,300 \mathrm{~g}$. The father, 36 years old, was healthy. The mother, 33 years old, had, when pregnant, complained of tachycardia, goiter and hypertension since the 5th month of her pregnancy. Under the diagnosis of thyrotoxicosis, the mother had been treated with Mercazole (Methimazol) (20-60 mg per day) until the time of delivery. In spite of the treatment, the basal metabolic rate (B.M.R.) remained at an increased level $(+22.5 \sim 57 \%)$. At birth, the baby was normal except for diffuse hyperpigmentation of the skin of the entire body. Since the second week of life, the patient had been given cortisone (5-15 mg/day) for about 3 weeks. The hyperpigmentation of the skin showed a tendency to decrease gradually in intensity. At the age of 28 days, the patient was referred to our Clinic for further examination, especially for a further treatment of the remaining hyperpigmentation. On admission, her weight and height were within normal limits. Moderate hyperpigmentation of the skin was still noticeable. Conjunctivae were neither anemic nor icteric. The chest was clear to percussion and auscultation. The abdomen was slightly distended. The liver was palpable 
one fingerbreadth below the costal margin, but the spleen was not palpable. There was, otherwise, no abnormality on physical examination.

Examination of blood showed hemoglobin of $12.6 \mathrm{~g} / \mathrm{dl}$, hematocrit $42 \%$, R.B.C. $427 \times 10^{4} / \mathrm{mm}^{3}$, and W.B.C. $8,900 / \mathrm{mm}^{3}$ with a differential count of $0.5 \%$ basophils, $2.5 \%$ eosinophils, $45.0 \%$ lymphocytes, $10.5 \%$ monocytes and $41.5 \%$ neutrophils without nuclear shift to the left.

Serum electrolytes were $109.5 \mathrm{mEq} / \mathrm{L}$ for chloride, $6.0 \mathrm{mg} / \mathrm{dl}$ for calcium, and $7.80 \mathrm{mg} / \mathrm{dl}$ for phosphorus. Serum protein was $6.2 \mathrm{~g} / \mathrm{dl}$ of which albumin was $56 \%, \alpha$-globulin $12.2 \%, \beta$-globulin $10.6 \%$, and $\gamma$-globulin $21.2 \%$.

The liver function tests showed 2 Meulengracht units for icteric index, 0.1 unit for thymol turbidity test, 0.8 unit for zinc sulfate test, 3 units for serum glutamic oxaloacetic transaminase, and 2 units for serum glutamic pyruvic transaminase.

The fasting blood sugar was $97.0 \mathrm{mg} / \mathrm{dl}$, and serum total ascorbic acid $1.51 \mathrm{mg} / \mathrm{dl}$.

The urine was straw-colored and clear with $\mathrm{pH}$ of 6.0 , and contained no protein and sugar; aceton was negative. Urobilinogen excretion was within normal limits. The ferric chloride test for phenylpyruvic acid was negative. Millon's test was positive. The excretion of $17 \mathrm{KS}$ and $170 \mathrm{HCS}$ was $\mathrm{mg} / \mathrm{day}$ and $\mathrm{mg} /$ day, respectively.

Feces were yellow-colored and negative for occult blood. Ophthalmological examination revealed no abnormality.

Among results of the routine examinations above mentioned, Millon's test of the urine was the only positive reaction. This test is known to be specific for tyrosine or its derivatives. The following analyses, therefore, were carried out in order to investigate a nature of substance or substances which reacted positively to Millon's test.

Special studies:

Quantitative determination of free amino acids, by Tada's method, ${ }^{23,24}$ ) was carried out upon urine and serum from the patient. The results, as were shown in Table I, revealed a remarkably higher value ${ }^{23,24}$ ) of free amino acids in serum but urinary output of free amino acids remained to be within normal limits.

Paper chromatography of urinary amino acids was performed according to the method of Ghadimi and Schwachmann. ${ }^{25}$ ) The paper chromatogram of urinary amino acids indicated excessive amounts of tyrosine and an unknown spot close by that of tyrosine (cf. Fig. 1). The latter was considered to be spot of DOPA (see below).

The tyrosine contents in serum and urine from the patient were estimated by Ceriotti and Spandrio's method. ${ }^{26)}$ Serum tyrosine level was found to be 13.6 $\mathrm{mg} / \mathrm{dl}$ which was markedly higher than normal range $(1.4-2.4 \mathrm{mg} / \mathrm{dl}),{ }^{27,28}$ ) and it was also found that urinary excretion of tyrosine was definitely increased (cf. Table II).

Unexpectedly, it was found that the urine of the patient turned to 
TABLE I Tyrosipe and Amino. Acid-nitrogen in Serum of Our Own Patient

\begin{tabular}{c|c|c|c}
\hline Date of examination & $\begin{array}{c}\text { Age } \\
\text { (days) }\end{array}$ & $\begin{array}{c}\text { Amino acid-nitrogen } \\
(\mathrm{mg} / \mathrm{dl})\end{array}$ & $\begin{array}{c}\text { Tyrosine } \\
\text { (mg/dl) }\end{array}$ \\
\hline Feb. 16 & 12 & 12.9 & 13.6 \\
Mar. 11 & 35 & & 4.5 \\
Mar. 14 & 38 & & 5.3
\end{tabular}

Polient T.A

|Feb. 27 \}

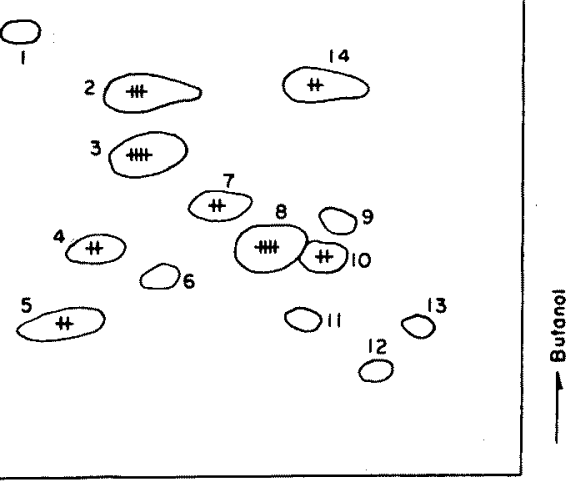

Phenol

Fig. 1. Paper chromatogram of urine of our own patient (Feb. 27)
1) Valine ?
6). Glutamine
11) Aspartic acid
2) Tyrosine
7) Threonine
12) Cysteine?
3) Alanine
8) Glycine
13) Cysteic acid?
4) Arginine
9) Glutamic acid
14) DOPA?
5) Histidine
10) Serine

TABLE II. Urinary Output of Tyrosine, pHPPA and pHPLA in Oux Own Patient

\begin{tabular}{c|c|c|c|c}
\hline Date of examination & $\begin{array}{c}\text { Age } \\
\text { (days) }\end{array}$ & $\begin{array}{c}\text { Tyrosine } \\
(\mathrm{mg} / \mathrm{day})\end{array}$ & $\begin{array}{c}\text { pHPPA } \\
(\mathrm{mg} / \text { day })\end{array}$ & $\begin{array}{c}\text { pHPLA } \\
(\mathrm{mg} / \mathrm{day})\end{array}$ \\
\hline Feb. 27 & 23 & 50.0 & 27.0 & 11.8 \\
Mar. 7. & 31 & 10.5 & 9.2 & 10.8 \\
Mar. 27 & 51 & 9.9 & 3.8 & 22.3
\end{tabular}

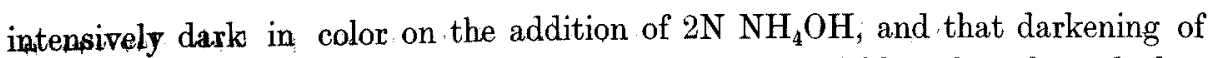
the urine on the addition of $\mathrm{NH}_{4} \mathrm{OH}$ took place quickly when heated, but very slowly when kept, at room temperature. Darkening of urine by $\mathrm{NH}_{4} \mathrm{OH}$, 
is known to be one of characteristics for alkaptonuria, in which homogentisic acid is known to be a causative substance for darkening of urine. However, darkening of urine did not take place on the addition of $\mathrm{NaOH}$ in the case of our own patient, while homogentisic acid turned into dark black in color on addition of $\mathrm{NaOH}$ as well as of $\mathrm{NH}_{4} \mathrm{OH}$.

As will be seen from Table III, DOPA solution $(0.2 \%)$ and the urine sample from our patient showed the same behavior of change in color on addition of $\mathrm{NaOH}, \mathrm{NH}_{4} \mathrm{OH}$ or $\mathrm{FeCl}_{3}$, but not with Benedict's reagent. DOPA solution $(0.2 \%)$ indeed was positive to Benedict's reagent, but the urine sample was negative. This difference might be explained by such an assumption that concentration of DOPA probably contained in the urine sample was not large enough to bring about the reduction of Benedict's reagent. The concentration of DOPA required for developing the positive Benedict reaction is said to be more than $0.1 \%$.

TABLE III. Changes in Color of DOPA-, Homogentisic Acid-solution and of the Urine Sample from Our Own Patient on Addition with $\mathrm{NaOH}$, $\mathrm{NH}_{4} \mathrm{OH}, \mathrm{FeCl}_{3}$, or Benedict's Reagent

\begin{tabular}{l|l|l|l|l}
\hline & \multicolumn{4}{|c}{ On addition of } \\
\cline { 2 - 4 } & \multicolumn{1}{|c|}{$\mathrm{NH}_{4} \mathrm{OH}$} & $\mathrm{NaOH}$ & $\mathrm{FeCl}_{3}$ & $\begin{array}{c}\text { Benedict's } \\
\text { reagent }\end{array}$ \\
\hline Homogentisic acid & $\begin{array}{l}\text { Intensely } \\
\text { dark (prompt) }\end{array}$ & $\begin{array}{l}\text { Intensely } \\
\text { dark }\end{array}$ & $\begin{array}{l}\text { Evanescently } \\
\text { blue }\end{array}$ & Positive \\
\hline DOPA & $\begin{array}{l}\text { Intensely } \\
\text { dark (by heating) }\end{array}$ & $\begin{array}{l}\text { Faintly } \\
\text { dark }\end{array}$ & Dark blue & Positive \\
\hline $\begin{array}{l}\text { Urine sample from } \\
\text { our own patient }\end{array}$ & $\begin{array}{l}\text { Intensely } \\
\text { dark (by heating) }\end{array}$ & $\begin{array}{l}\text { Faintly } \\
\text { dark }\end{array}$ & Dark blue & Negative \\
\hline
\end{tabular}

As will be seen from Fig. 3, similar patterns of absorption spectrum were observed in both the ammoniated DOPA solution (0.2\%) and the urine sample added with $\mathrm{NH}_{4} \mathrm{OH}$.

Basing upon the results above obtained, it may be reasonable to assume that the substance responsible for the urine darkening in color on addition with $\mathrm{NH}_{4}$ OH was possibly DOPA or DOPA-like substance.

By using Medes's method ${ }^{7)}$, parahydroxyphenyllactic acid (pHPLA) and parahydroxyphenylpyruvic acid (pHPPA) were determined, and the latter was identified in an increased amount on Feb. 27 when the hyperpigmentation was noticed to a marked degree (cf. Table II).

Further clinical course of the patient and biochemical findings:-

During the hospitalization, hyperpigmentation of the patient showed a tendency to gradual decrease without any special medication-the above mentioned cortisone treatment was performed before the hospitalization-, and the 
Potient T.A

(Mar. 27)
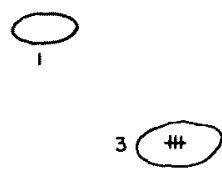

4

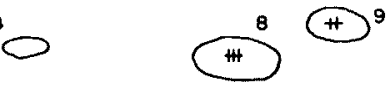

12

Phenol

Fig. 2. Paper chromatogram of urine of our own patient (Mar. 27)
1) Valine?
3) Alanine
4) Arginine
8) Glycine
9) Glutamic acid
12) Oysteine?

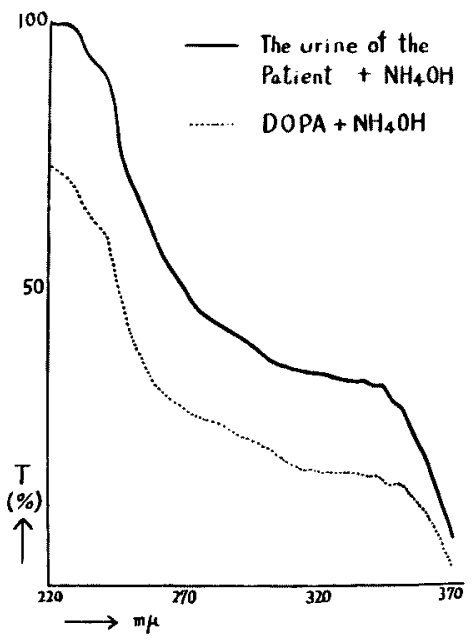

Fig. 3. Patterns of absorption spectrum

The urine of our own patient added with $\mathrm{NH}_{4} \mathrm{OH}$ DOPA solution added with $\mathrm{NH}_{4} \mathrm{OH}$

hyperpigmentation disappeared almost completely at the age of 60 days. On about the 30th day of life when the hyperpigmentation was improved considerably, the patient's urine was revealed to be normal as to tyrosine concentration as well as to chromatographic findings of urinary amino acids. Further, the darkening of the urine on addition with $\mathrm{HN}_{4} \mathrm{OH}$ remained negative (cf. Fig. 2). 


\section{DISCUSSION}

1) Urinary findings in our case differ from tyrosinosis or tyrosyluria in infants.

In our case characteristic urinary finding was a transient excretion of considerable amounts of tyrosine, p-hydroxyphenylpyruvic acid (pHPPA) and dihydroxyphenylalanine (DOPA) or DOPA-like substance.

In 1939 Levine $e t a l{ }^{1)}$ reported that urinary output of pHPPA in absence of appreciable amounts of tyrosine, DOPA and homogentisic acid, was found in premature infants fed on high-protein, ascorbic acid free diet. Since then, an increased urinary output of tyrosine and its deaminated derivatives (pHPPA) and p-hydroxyphenyllactic acid (pHPLA), termed "tyrosyluria", following the ingestion of L-tyrosine was found not only in infants ${ }^{2)}$ and adults ${ }^{5)}$ suffering from frank scurvy but also in those with preclinical scurvy. The occurrence of tyrosyluria was also reported on the cases with severe hepatic damage ${ }^{3}$ ) and pernicious anemia. ${ }^{4}$ ) In 1960 , Bloxam et al. $\left.{ }^{6}\right)$ found 14 infants with urinary excretion of large amounts of pHPPA, pHPLA and tyrosine out of 1276 infants tested. These infants with tyrosyluria were those fed on a normal diet with supplementary ascorbic acid. They were well with no evidence of hepatic dysfunction and aged up to 68 days. An immaturity of pHPPA-oxidase ${ }^{6}$ ) was ascribed to the development of tryosyluria in these infants.

In all these cases above mentioned ${ }^{1-6)}$ dihydroxyphenylalanine (DOPA) was absent in the urine and this was a significantly different point from our own case, in which DOPA or a DOPA-like substance was excreted in urine besides tyrosine and pHPPA.

Urinary excretion of DOPA associated with tyrosyluria was found in a case of tyrosinosis?), and it occurred only when loaded with a high dose of L-tyrosine. In the case of tyrosinosis, consistent urinary excretion of large amounts of pHPPA was a characteristic finding, while only a transient tyrosyluria was found in our own case.

So it may be said that our own case characterized by a transient tyrosyluria associated with DOPA-uria differs from tyrosinosis? ${ }^{\text {) }}$ and from tyrosyluria of infants ever reported. ${ }^{1-6)}$

2) In our own case it is probable that during pregnancy the mother remained to be thyrotoxic despite methimazol medication, because her basal metabolic rates were found to be about $+20 \%$ throughout the whole period of pregnancy.

Maternal thyroxine is known to cross placenta and to be transferred into the fetus. ${ }^{8)}$ In our own case, therefore, it may be reasonably assumed that excessive amounts of thyroxine were transmitted into the fetus. At the same time, methimazol taken by the mother was also transmitted through placenta ${ }^{9}$ ) into the 
fetus and it acted presumably as a depressant upon thyroxine synthesis in the fetal thyroid glands.

It may be supposed that the inhibition of thyroxine synthesis by methimazol in the fetal thyroid glands resulted in sparing of tyrosine for thyroxine synthesis, and further in an accumulation of tyrosine in the fetal serum.

3) In our own case there was a possible inhibition of tyrosine-transaminase activity in the fetal liver by the thyroxine transferred from the mother.

In our own case there was a high tyrosine level in serum associated with urinary output of tyrosine, DOPA and pHPPA. This finding was considered as a strong evidence for existence of a block in tyrosine-transaminase in tyrosine metabolism. ${ }^{10)}$ An excessive amount of the thyroxine transmitted from the mother was a factor responsible for the inhibition of tyrosine-transaminase activity, because thyroxine would show, according to Litwack, ${ }^{11}$ ) a strong inhibitory effect on liver tyrosine-transaminase in rats. Urinary excretion of pHPPA in the case with block of tyrosine-transaminase was explained in the same way as excretion of phenylpyruvic acid in the case with phenylketonuria in which phenylalanine hydroxylase is absent, as was suggested by La Du. ${ }^{10}$ )

The tyrosine-transaminase activity in the liver during fetal life is very low, ranging between 10 and $20 \%$ of that of adult liver. ${ }^{12)}$ However, in rats the enzyme activity rises at least tenfold between the second and twelfth hour of life, in response to a variety of factors including adrenal cortical function ${ }^{13}$ most prominently. As above quoted, adrenocortical hormone is an important factor for activation of the tyrosine-transaminase system. In our own case there were no clinical symptoms and signs suggesting adrenocortical insufficiency, and urinary $17 \mathrm{KS}$ was found to be normal.

No injurious effects of methimazol upon adrenal glands were reported. ${ }^{14}$ )

4) A possible mechanism by which hyperpigmentation of the skin of our own case was brought about.

As above described in our own case there was an accumulation of tyrosine in serum, which was considered to have resulted mainly from a block of tyrosinetransaminase and partially from a block of thyroxine synthesis. Furthermore, presence of DOPA in urine was taken as a strong evidence for acceleration of the reaction tyrosine $\rightarrow$ DOPA $\rightarrow$ melanin.

Why was the melanin synthesis (tyrosine $\rightarrow$ melanin) accelerated? In this respect the effect of melanophore stimulating hormone (MSH) upon melanin synthesis should be taken into consideration. According to Diczfalusy ${ }^{15}$ MSH was detected in human fetal pituitary glands. In 1951 Frieden ${ }^{16}$ ) reported an increase in MSH concentration in rat pituitary glands by feeding of desiccated thyroid powder and its decrease following thyroidectomy or the administration of 
thiouracil. In $1944 \mathrm{Juhn}^{17}$ ) reported a decrease in pigmentation of feather of Brown Leghorn capons following thyroidectomy or thiouracil administration. In adult cases with Basedow's disease or thyrotoxicosis, hyperpigmentation of the skin was found to be in $19 \sim 64 \%$ of the cases and a marked blanching of it was observed after thyroidectomy. ${ }^{18)}$

Basing upon these findings suggesting close relationship between melanin synthesis and thyroid function, it was supposed that the hyperpigmentation of the skin of our own case had resulted from an increased activity of MSH due to the excessive amounts of thyroxine from the mother in addition to a high level of serum tyrosine as a precursor of melanin. This assumption was also supported by the fact that blanching of the hyperpigmentation was brought about after onset of steroid therapy given to our own case, because marked increase in tyrosine-transaminase activity in rat livers following administration of hydrocortisone was reported by $\mathrm{Lin}^{19}$ ) on one hand, and remarkable decrease in the activity of $\mathrm{MSH}$ promptly after an administration of hydrocortisone was reported by Sulman ${ }^{20)}$ on the other hand.

5) Has there been any reported case of hyperpigmented infants born of thyrotoxic mothers with or without antithyroid drugs?

In 1959 Javett et al. ${ }^{21)}$ reviewed 9 cases, including 2 cases of their own, of neonatal thyrotoxicosis published up to that time. These infants were born of mothers who were suffering or had suffered from thyrotoxicosis with or without antithyroid medication. As prominent clinical features of these newborns goiter and/or exophthalmos were noticed, but no mention was made of hyperpigmentation of the skin in any of the cases included in their report. ${ }^{21)}$ In 1952 Hepner ${ }^{22}$ investigated the effects of thiouracil or its derivatives upon fetus by reviewing 30 pregnant women with hyperthyroidism treated with antithyroid drugs. In this report of his there was no fetal case with hyperpigmentation of the skin.

We feel quite strange why there has been no description of hyperpigmentation of the skin of newborn with hyperthyroidism, although the hyperpigmentation has been found up to $64 \%$ of the adult ${ }^{18)}$ cases with hyperthyroidism!

\section{SUMMARY AND CONCLUSIONS}

1) Hyperpigmentation of the skin was described as a prominent feature of an infant born of a thyrotoxic mother with methimazol medication.

2) Urinary excretion of dihydroxyphenylalanine (DOPA) or DOPA-like substance was found, suggesting an evidence for an increased melanin synthesis in our own case.

3) A mechanism for an acceleration of the pathway tyrosine $\rightarrow$ DOPA $\rightarrow$ melanin has been explained from the following two points:- 
i) There was a high tyrosine level in serum. This finding associated with urinary output of p-hydroxyphenylpyruvic acid gave a strong evidence for the existence of a block of tyrosine-transaminase. An excessive amount of thyroxine transferred from the mother was presumably a factor responsible for the inhibition of tyrosine-transaminase in the fetal liver.

ii) There was a possible increase of activity of the melanophore-stimulating hormone. This was probably caused by an excessive amount of thyroxine transmitted from the mother.

4) This case may, within our literature survey, be the first case reported with such an anomaly.

\section{References}

1) Levine, S.Z. et al., Science, 1939, 90, 620 .

2) Morries, J.E. et al., J. Clin. Inv., 1950, 29, 325.

3) Felix, K., et al., Zeit. Phys. Chem., 1951, 287, 141.

4) Swendseid, M.E., J. Lab. Clin. Med., 1947, 32, 1242.

5) Rogers, W.E. Jr. \& Gardner, F., J. Clin. Inv., 1950, 29, 325.

6) Bloxam, H.R. et al., Biochem. J., 1960, 77, 320.

7) Medes, G., ibid., 1932, 26, 915.

8) Grumbach, L.M. \& Werner, S.C., J. Clin. Endocrinol., 1956, 16, 1392.

9) Scarizza, P.M., Minerva pediat. Tor., 1954, 6, 433.

10) La Du, B. N., The Metabolic Basis of Inherited Disease, McGraw-Hill, New York, Tronto, London, 1960, p. 383.

11) Litwack, G., Proc. Soc. Exp. Biol. \& Med., 1956, 93, 13.

12) Seremi, F. et al., J. Biol. Chem., 1959, 234, 609.

13) Lin, C.E.E. \& Knox, W.E., ibid., 1958, 233, 1186.

14) Tusch, E., Arzneimittelforsch., 1959, 9, 427.

15) Diczfalusy, E., Acta Endocr. (Den.), Suppl., 1962, 67, 37.

16) Frieden, E.D., Endocrinol., 1951, 49, 557.

17) Juhn, M., ibid., 1944, 35, 278.

18) Maruta, K., Nippon Naibunpi Gakkai Zasshi (Jap.), 1953, 29, 91.

19) Lin, E.C.C. \& Knox, W.E., Biochim. Biophys. Acta, 1957, $26,85$.

20) Sulman, F.G., J. Clin. Endocrinol., 1956, 16, 755.

21) Javett, S.N. et al., Pediatrics, 1959, 24, 65.

22) Hepner, W.R. Jr., Am. J. Obst. \& Gyn., 1952, 63, 869.

23) Tada, K., Pediatrica Japonica, 1958, 1, 2, 1.

24) Tada, K., Shonika Rinsho (Jap.), 1963, 16, 479.

25) Ghadimi, H, \& Schwachmann, H., Am. J. Dis. Child., 1960, 99, 457.

26) Ceriotti, G. \& Spandrio, L., Biochem. J., 1957, 66, 607.

27) Partington, M.W. \& Lewis, E.J. M., J. Pediat., 1963, 62, 3, 348.

28) Hsia, D.Y. et al., New Engl. J. Med., 1962, 267. 1067. 